\title{
Assessment of Intelligence of Duchenne Muscular Dystrophy (DMD) Children and Adolescents and Parental Stress in a Muscular Dystrophy Center in Nepal
}

\author{
Rana $\mathbf{M}^{1}$, Adhikari $\mathbf{S}^{2}$, Pradhan $\mathbf{M}^{3}$ \\ ${ }^{1}$ Dr. Mita Rana, PhD, Associate Professor. ${ }^{2}$ \\ Ms.Sirjana Adhikari, M.Phil. (Clinical \\ Psychology), ${ }^{3}$ Monalisa Pradhan, M.Phil. \\ (Clinical Psychology). All from the Department \\ of Psychiatry and Mental Health, Tribhuvan \\ University Teaching Hospital (TUTH), Institute \\ of Medicine (IOM), Kathmandu, Nepal.
}

\author{
Address for correspondence: \\ Assoc. Prof. Dr. Mita Rana \\ Department of Psychiatry and Mental Health, \\ Tribhuvan University Teaching Hospital \\ (TUTH), \\ Institute of Medicine (IOM), Kathmandu, Nepal. \\ Tel No; +9779803003925 \\ E-mail: ranamita@yahoo.co.uk
}

\begin{abstract}
Acknowledgements: The authors acknowledge Muscular Dystrophy FoundationNepal.

Funding: Nil

Conflict of Interest: None

Permission from IRB: Yes

Ethical dilemmas faced during study: None
\end{abstract}

\section{How to cite}

Rana M, Adhikari S, Pradhan M. Assessment of Intelligence of Duchenne Muscular Dystrophy (DMD) Children and Adolescents and Parental Stress in a Muscular Dystrophy Center in Nepal J Nepal Paediatr Soc 2016;36(3):227-231.

doi: http://dx.doi.org/10.3126/jnps.v36i3.16357

This work is licensed under a Creative Commons Attribution 3.0 License.

\begin{abstract}
Introduction: Duchene Muscular Dystrophy (DMD) is an X-linked developmental disorder characterized by progressive muscle weakness, demanding many psychosocial adjustments for both parents and children; learning and behavioral problems, changing values, expectations, roles and responsibilities, separation and loss that lead to parental stress. This study is an attempt to explore the level of Intelligence Quotient of children and adolescents with DMD and further elucidate aspects of parental stress. Material and Methods: The study involved 30 children and adolescents with DMD, chosen by convenient sampling method and one parent each, during their regular medical evaluation at the Duchene Muscular Dystrophy Foundation in Nepal. Measures used to collect data were the Draw a Man Test and Cohen's Perceived Stress Scale. Results: Age of the DMD children and adolescents ranged between 4 to 19 years with mean age $12.01 \pm 6.26$ years, $93.94 \%$ were male. $53.33 \%$ of the parents reported having average level of stress and $63.33 \%$ of DMD children and adolescents had average level of Intelligence Quotient (IQ > 70), 16.67\% had mild (IQ between $50-69$ ) and $10 \%$ each were found to have moderate and severe intellectual disability. Significant negative correlation $(r$ $=-0.393, p=0.05$ ) was found between the level of intellectual functioning of DMD children and level of parent's perceived stress.Conclusion: Most of the parents experienced average to severe level of stress based on the duration of illness and the level of intellectual functioning of their DMD child. Parents experienced greater level of stress with children having low intelligence.
\end{abstract}

Key words:Duchenne Muscular Dystrophy (DMD), Parental stress, Intelligence Quotient.

\section{Introduction}

$\mathrm{D}$ uchenne muscular dystrophy (DMD) is an X-linked developmental disorder that causes progressive muscle weakness which occurs with an incidence of about 30 per 100,000 live born males ${ }^{1}$. The gene involved normally codes for a protein called dystrophin, which localizes to muscle, and dystrophin-like products, which localize to 
the central nervous system. In children with DMD, these products are missing due to a deletion in the gene. As the genetic deletion that causes DMD is located on the $X$ chromosome, boys have the more severe, fatal form of the disease.

This disease has long been associated with intellectual impairment ${ }^{2}$. Delay in global development and language disorders can constitute the signs of onset in this disease. A meta-analysis ${ }^{3}$, documented intelligence quotients in 721 children and adults with Duchenne muscular dystrophy, and indicated that the overall mean intelligence quotient was 82 (approximately 1 S.D. below the population mean). $19 \%$ demonstrated an intelligence quotient below 70 and $3 \%$ demonstrated an intelligence quotient of less than 50 (indicating moderate to severe intellectual disability).

There is ample evidence of cognitive involvement in DMD, although the presentation is much more variable. On average, the mean $I Q$ in children with DMD is shifted down one standard deviation from the population mean, and verbal intelligence scores are more compromised than performance intelligence scores $^{4,5}$. There are considerable data attesting to specific deficits in children and adolescents with DMD as opposed to a global deficit', 6, 7, 8,9,10. Verbal disability consisting of poor expressive verbal abilities, deficits in verbal working memory deficits in short-term memory, and specific disabilities in learning to read, write, and calculate, with relatively intact visuospatial cognitive abilities, are more frequently reported cognitive deficits in children with Duchenne muscular dystrophy. However, no relationship has been documented between levels of muscular degeneration and cognitive impairment ${ }^{11,12}$.

Prior research has examined a variety of factors related to stress in parents of chronically ill children. In a study of children with developmental disabilities, family variables, particularly family resources, were found to predict stress, and impairment in child social skills had a stronger relationship to parental stress than any other aspect of functioning (i.e., motor, cognitive, communication, adaptive behavior $)^{13}$. These studies suggest that interpersonal or behavioral variables are a source of parental stress, beyond aspects of daily care or medical concerns. The present study sought to further elucidate aspects of parental stress in families of boys with DMD. Generally, prior studies of stress in parents of children with a chronic illness indicated that mothers of disabled and chronically ill children report greater parental stress and overall distress. The presence of problem child behaviors consistently predicted maternal stress. Stress related to child behavior was higher in the DMD versus the normative group, possibly due to increased problem behaviors, particularly in social interactions, rather than due to the physical demands of the disease alone ${ }^{14}$.

The Muscular Dystrophy Foundation-Nepal (MDFNEPAL) is a Non- Profit making voluntary organization formulated in initiation of Parents Projects Muscular Dystrophy (PPMD-Nepal) and Social workers registered in Government of Nepal, in 2003. Mission of the organization is to create nation-wide awareness of the disease, find viable treatment and cure for MD, parental counseling, establish rehabilitation activities and streamline the stakeholders with latest development. Considering the multiethnic composition of Nepali population, the incidence of Muscular Dystrophy (MD) Disorders is similar to the rest of the world. The government does not have records on how many persons are suffering from Muscular Dystrophy (MD). It is estimated that there may be more than $20-25,000$ (approx.) with various types of MDs based on the current population growth of the country, $1.9 \%$ per annum ${ }^{15}$.

Level of intellectual functioning itself would be a source of parental stress if it is below average. So, present study is an attempt to explore the level of intellectual functioning among the children and adolescents with muscular dystrophy and sought to further elucidate aspects of parental stress in families with DMD. Generally, prior studies of stress in parents of children with a chronic illness indicated that parents of disabled and chronically ill children report greater parental stress and overall distress. We therefore focused upon stress levels reported by parents because, as a primary caregiver, they may be at particular risk for increased stress.

\section{Material and Methods}

Participants of the study were 30 children and adolescents with Duchene Muscular Dystrophy and their parents selected via convenient sampling method. Measures used to collect data were the Draw a Man Test (DMT) and the Cohen's Perceived Stress Scale (PSS) ${ }^{16 .}$ The Draw a Man Test (DMT) developed by Florence L. Goodenough (1926) ${ }^{17}$ was used to measure the level of intellectual functioning. The test-retest reliability of DMT ranges from 0.68 to 0.80 and it was used as an indicator of cognitive level and socio-emotional development ${ }^{17}$.

The Perceived Stress Scale (PSS) was assessed with parents to measure the level to which they considered their life stressful, unpredictable and controllable they appraised their life. The original version had 14 items, 
seven negatively stated and seven positively stated. Two short forms are available, one with 10 items (six negatively stated and four positively stated items) and the other with four items (two negatively stated and two positively stated) with items answered on a four point Likert scale-ranging from strongly agree to strongly disagree where stress is measured in terms of high stress or average stress. The 10 -item versions showed adequate internal consistency such as a Cronbach's alpha of 0.78 and test-retest reliability of 0.86 using a 7-day interval, 0.77 using a two-week interval ${ }^{16}$.

Ethical clearance was taken from the Institutional Review Board of Institute of Medicine and MDFNepal board committee and only those children and adolescentwho gave informedconsent and whose parents also consented were enrolled in the study during their regular medical evaluation, in the annual health camp of Duchene Muscular Dystrophy Foundation, Nepal.

\section{Results}

\section{Characteristics of the DMD children and adolescents}

Table 1 shows the distribution of the children and adolescents by their age and sex. In the study $93.34 \%$ of the children and adolescents were males and $6.66 \%$ were females. Age of the participants ranged between
4 to 19 years with mean age of the children and adolescents being 12.01 years. $50 \%$ of the participants were between ages of 4-11 years, and another $50 \%$ were from the age group 12-19 years of age.

Table 2 shows that majority of the children and adolescents (63.33\%) had average level of intelligence level as the Intelligence Quotient (IQ) is more than 70 and $36.67 \%(n=11)$ of the children and adolescents had below average level of intellectual functioning. Out of the low intellectual functioning, $16.67 \%$ of the children and adolescents had mild intellectual disability (IQ range between $50-69$ ) and $10 \%$ had moderate and $10 \%$ had severe intellectual disability (IQ range between 35-49).

Table 3 indicates the level of perceived stress of the parents of muscular dystrophy patients. $53.33 \%$ of the parents had average level of stress associated with the disease of their child and adolescents and $46.67 \%$ had high level of perceived stress.

Table 4 shows that there is statistically significant negative correlation $(r=-.393, p=0.05)$ between the level of intellectual functioning among the children and adolescents with muscular dystrophy and the level of their parent's perceived stress. It indicates that an increase in the level of intellectual functioning is associated with decrease in the level of perceived parental stress.

Table 1: Distribution by age and gender

\begin{tabular}{cccccc}
\hline $\begin{array}{c}\text { Age of the children and } \\
\text { adolescents (in years) }\end{array}$ & Male $(\mathbf{n})$ & Percent (\%) & Female (n) & Percent (\%) & $\begin{array}{c}\text { Percentage } \\
\text { Total (\%) }\end{array}$ \\
\cline { 2 - 6 } & 14 & 46.67 & 1 & 3.33 & 50 \\
\hline $4-11$ & 14 & 46.67 & 1 & 3.33 & 50 \\
\hline $12-19$ & $\mathbf{2 8}$ & $\mathbf{9 3 . 3 4}$ & $\mathbf{2}$ & $\mathbf{6 . 6 6}$ & $\mathbf{1 0 0}$ \\
\hline Total $(\mathbf{N}=\mathbf{3 0})$ & & &
\end{tabular}

Source: Field Study, 2015

Table 2: Intelligence level of muscular dystrophy children and adolescents

\begin{tabular}{|c|c|c|c|}
\hline Intelligence Quotient (IQ) & $\begin{array}{c}\text { Number of Children and } \\
\text { adolescents (n) }\end{array}$ & Percentage (\%) & \\
\hline Average IQ (IQ>70) & 19 & 63.33 & Average IQ: $n=19(63.33 \%)$ \\
\hline $\begin{array}{l}\text { Mild ID } \\
\text { (IQ between 50-69) }\end{array}$ & 5 & 16.67 & \multirow{5}{*}{$\begin{array}{l}\text { Intellectual Disability (ID) } \\
\text { Low IQ: } n=11(36.67 \%)\end{array}$} \\
\hline $\begin{array}{l}\text { Moderate ID } \\
\text { (IQ between 35-49) }\end{array}$ & 3 & 10 & \\
\hline $\begin{array}{l}\text { Severe ID } \\
\text { (IQ between 20-34) }\end{array}$ & 3 & 10 & \\
\hline $\begin{array}{l}\text { Profound ID } \\
(I Q<20)\end{array}$ & - & - & \\
\hline Total (N) & 30 & 100 & \\
\hline
\end{tabular}

Source: Field Study, 2015(ID= Intellectual Disability) 
Table 3: Perceived stress among parents of muscular dystrophy children and adolescents

\begin{tabular}{ccc}
\hline Level of perceived parental stress & Number of parents & Percentage \\
\hline Average stress & 16 & 53.33 \\
\hline High stress & 14 & 46.67 \\
Total $(\mathbf{N}=\mathbf{3 3})$ & $\mathbf{3 0}$ & $\mathbf{1 0 0}$ \\
\hline
\end{tabular}

Source: Field Study, 2015

Table 4: Relationship between intellectual level and perceived parental stress

\begin{tabular}{ccc}
\hline & Level of parent stress & Level of intellectual functioning \\
\cline { 2 - 3 } Level of parental stress & 1 & - \\
Level of intellectual functioning $(\mathrm{N}=33)$ & $-.393^{*}$ & 1 \\
\hline
\end{tabular}

${ }^{*}$. Correlation is significant at the 0.05 level (One- tailed)

\section{Discussion}

Duchenne Muscular Dystrophy (DMD) which is both chronic and terminal may be characterized as a "complex chronic condition" in that it involves specialized and time-consuming care, even when the terminal phase lies years in the future. Children with Duchenne are at increased risk for developmental delays. The most common delays are in gross motor skills such as sitting, walking, and running. However, children with Duchenne are also at increased risk for delays in other areas such speech/language development, motor planning, and fine motor dexterity. Interventions for developmental delays (e.g., speech/language, physical, and occupational therapies) should be targeted on improving specific skills. Interventions typically involve various therapies focused on improving specific skills ${ }^{18}$.

Similar to the general population, IQ scores in DMD can range from well above average to below average. Most DMD children have an IQ that is in the normal range. However, they are also at increased risk for having an IQ that is below average or in the mental retardation range (IQ score less than 70). DMD children may also have a specific pattern of cognitive strengths and weaknesses that may not be accurately represented in an overall IQ score $^{18}$. Problems with short-term verbal memory (also called working memory) are the most common finding, and can be present even in children with a high IQ. This has an impact on the amount of information they can takein and hold at any one time ${ }^{19}$.

Results of the present study show pattern of intellectual functioning of children and adolescents with DMD and parental stress. Mean age of the patients was 12.01 years and $93.94 \%$ of the patients were male. As the disease itself is associated with $\mathrm{X}$-linked chromosome which might be the cause of overrepresentation of boys within the study and usually they have severe and fatal course in comparison to girls ${ }^{3}$.
In the study $63.33 \%$ of children and adolescents had IQ more than $70,16.67 \%$ had mild intellectual disability and $20 \%$ had moderate to severe intellectual disability. These findings are somewhat similar with previous studies ${ }^{3}$. As literature suggests that most boys with DMD function within the normal limits of intelligence, about $19 \%$ of the DMD population is mentally retarded (as compared with $2-3 \%$ in the general population) ${ }^{3}$. The extent of cognitive involvement is variable across individuals but is not associated with physical severity and does not appear to be progressive ${ }^{11,12}$. Therefore children with intellectual impairment will need significantly more repetition, rehearsal, and practice to learn new academic information. Moreover, they would benefit from formal and special education. Therefore educational institutes, teachers and parents are recommended to create infrastructures to facilitate inclusion of DMD children and provide and promote special facilities for education, curricular activities and care ${ }^{18}$.

With regard to parental stress, about $46.67 \%$ parents reported to have high level of stress. Stress in parents of boys with DMD is elevated, possibly due to increased problem behaviors, particularly in social interactions, the physical demands of the disease itself $^{14}$. Majority of the parents in the study reported average level of stress which was associated with difficulty coping, often feeling difficulties piling up that could not be overcome and feeling angered and out of control. It is hypothesized that as stress was found to diminish over time as the disease progressed, rather than to increase. It appeared that parents learned to cope with the burdens associated with the disease and they are more resilient as the disease progresses. Another factor associated with the parental stress is the level of intellectual functioning among the boys with muscular dystrophy. In the study there was significant negative correlation ( $r=-0.393, p=0.05$ ) between the level of intellectual functioning among the children and 
adolescents with muscular dystrophy and the level of their parent's perceived stress. Parents whose children had low intelligence experienced greater level of stress.

\section{Conclusion}

Duchene Muscular Dystrophy (DMD) is associated with parental stress, which is related with the severity of illness and the level of intellectual functioning of children. Though parents experience parental stress,

\section{References}

1. Mendal JR, Griggs RC, Ptacek LJ. Diseases of muscle. In: Fauci AS, Braunwald E, Isselbacher KJ, et al., editors. Harrison's principles of internal medicine. Vol. 14. New York: McGraw-Hill; 1998. pp. 2473-2483.

2. Perumal AR, Rajeswaran J, Nalini A. Neuropsychological profile of duchenne muscular dystrophy. Appl Neuropsychol Child 2015; 4(1):49-57. Doi: 10.1080/21622965.2013.802649.

3. Emery A, Muntoni F. 3rd ed. Oxford University Press; Oxford: 2003. Duchenne muscular dystrophy.

4. Cotton S, Voudouris NJ, Greenwood KM. Intelligence and Duchenne muscular dystrophy: Full-scale, verbal, and performance intelligence quotients. Dev Med Child Neurol2001; 43:497-501.

5. D’Angelo MG, Lorusso ML, Civati F, Comi GP, Magri F, Del Bo R, Guglieri M, Molteni M, Turconi AC, Bresolin N. Neurocognitive Profiles in Duchenne Muscular Dystrophy and Gene Mutation Site. PediatrNeurol 2011;45(5):292-299. Doi: 10.1016/j.pediatrneurol.

6. Cotton SM, Voudouris NJ, Greenwood KM. Association between intellectual functioning and age in children and young adults with Duchenne muscular dystrophy: further results from a meta-analysis. Dev Med Child Neurol 2005; 47:257-65.

7. WicksellRK, Kihlgren M, Melin L, Eeg-Olofsson O. Specific cognitive deficits are common in children with Duchenne muscular dystrophy. Dev Med Child Neurol 2004; 46:154-9.

8. Hinton VJ, De Vivo DC, Nereo NE, Goldstein E, Stern $Y$. Selective deficits in verbal working memory associated with a known genetic etiology: the neuropsychological profile of Duchenne muscular dystrophy. J IntNeuropsycho/Soc 2001;7:45-54. it seems to be diminished over time and parents are more resilient with regard to the demands of children and adolescents with DMD. The important findings of this study is children with DMD, have average level of intellectual functioning which does not deteriorate with the disease. They will benefit from formal education with more emphasis on attention, phonological awareness, and verbal memory so they must be provided with this opportunity.

9. Hinton VJ, De Vivo DC, Fee R, Goldstein E, Stern $Y$. Investigation of poor academic achievement in children with Duchenne muscular dystrophy. Learn Dis Res Pract 2004;19: 146-54.

10. Hinton VJ, De Vivo DC, Nereo NE, Goldstein E, Stern Y. Poor verbal working memory across intellectual level in boys with Duchenne dystrophy. Neurology 2000;54:2127-132.

11. Allen JE, RodginDW. Mental retardation in association with progressive muscular dystrophy. Am J Dis Child 1960;100:208-11.

12. Karagan NJ. Intellectual functioning in Duchenne muscular dystrophy: a review. Psychol Bull 1979;86:250-59.

13. Smith TB, Oliver MN, Innocenti MS. Parenting stress in families of children with disabilities. $A m \mathrm{~J}$ Orthopsychiatr2001;71:257-61.

14. Nancy EN, Robert JF, Veronica JH. Parental Stress in Mothers of Boys with Duchenne Muscular Dystrophy. J PediatrPsychol 2003;28(7):473-84.

15. Muscular Distrophy Foundation [homepage on the internet]. Lalitpur, Kathmandu: Muscular Dystrophy Foundation, [updated 2015, May, cited 2015, December 21] Available from; http://www.mdfnepal. org/organisation-profile.html

16. Cohen S, Kamarck T, Mermelstein R. A global measure of perceived stress. J Health SocBehav1983;24:385-96.

17. Goodenough FL. Measurement of Intelligence by Drawings, 1926. World Book Co. New York.

18. Poysky JT.Learning and Behavior in Duchenne Muscular Dystrophy for parents and educators.Parent Project Muscular Dystrophy (US); 2011 Mar. 50.

19. HintonVJ, Fee RJ, Goldstein EM, De Vivo DC. Verbal and memory skills in males with Duchenne muscular dystrophy. Dev Med Child Neurol 2007;49(2):123-28. 